\title{
Negative ions in the auroral mesosphere during a PCA event around sunset
}

\author{
C. F. del Pozo ${ }^{1,3}$, E. Turunen ${ }^{2}$, T. Ulich ${ }^{2}$ \\ ${ }^{1}$ Department of Physics, University of Wales, Aberystwyth SY23 3BZ, UK \\ ${ }^{2}$ Sodankylä Geophysical Observatory, FIN-99600, Finland \\ ${ }^{3}$ Now at Ionosphere and Propagation Group, Engineering Department, Lancaster University, LA1 4YR, UK \\ E-mail: c.del.pozo@lancaster.ac.uk
}

Received: 6 October 1997 / Revised: 16 November 1998 / Accepted: 30 November 1998

\begin{abstract}
This is a study of the negative ion chemistry in the mesosphere above Troms $\varnothing$ using a number of EISCAT observations of high energy proton precipitation events during the last solar maximum, and in particular around sunset on 23 October, 1989. In these conditions it is possible to look at the relative importance of the various photodetachment and photodissociation processes controlling the concentration of negative ions. The data analysed are from several UHF GEN11 determinations of the ion-plasma ACF together with the pseudo zero-lag estimate of the 'raw' electron density, at heights between $55 \mathrm{~km}$ and $85 \mathrm{~km}$, at less than $1 \mathrm{~km}$ resolution. The power profiles from the UHF are combined with the 55-ion Sodankylä model to obtain consistent estimates of the electron density, the negative ion concentrations, and the average ion mass with height. The neutral concentrations and ion temperature are given by the MSIS90 model. These parameters are then used to compare the calculated widths of the ion-line with the GEN11 determinations. The ion-line spectrum gives information on the effects of negative ions below $70 \mathrm{~km}$ where they are dominant; the spectral width is almost a direct measure of the relative abundance of negative ions.
\end{abstract}

Key words. Ionosphere (auroral ionosphere; ion chemistry and composition; particle precipitation).

\section{Introduction}

We discuss some EISCAT UHF radar observations of solar energetic proton (SEP) precipitation events, also known as polar cap absorption or PCA. For a detailed description of a number of similar observations during

Correspondence to: C. F. del Pozo
1988, 1989, and 1990 (including the period discussed here) see Collis and Rietveld (1990), and Rietveld and Collis (1993). This study addresses the changes in the chemical composition of the mesosphere above Troms $\varnothing$ during sunset transition of 23 October 1989, within PCA conditions. This event was part of a series of exceptionally strong PCA occurrences between October 19 and 30. Figure 1 shows the $30 \mathrm{MHz}$ riometer absorption at Kilpisjärvi, $90 \mathrm{~km}$ southeast of Troms $\varnothing$, for the 23 October 1989 period.

Two different levels of absorption are clearly seen in Fig. 1, one at daytime and the other at nighttime. The sudden increase in absorption at sunrise and the rapid decrease at sunset, correspond to the 'switching' on and off of the solar production. Absorption levels give a direct indication of the amount of ionisation in the D-region due to the precipitation of the energetic ions. PCA events are associated with solar flares and may last from a few hours to several days. The accompanying flux of energetic ions may produce high levels of ionisation down to $50 \mathrm{~km}$ (or even lower).

We have combined the Sodankylä Ion chemistry model with a semi-empirical algorithm to estimate the precipitation production rate from the 'raw' electron density profile measured by the radar (del Pozo et al., 1997; del Pozo and Aylward, 1998). The energetic ions reach deep into the mesosphere producing sizeable ionisation, that can be measured by the radar (for electron densities greater than $\sim 5 \times 10^{6} \mathrm{~m}^{-3}$ ). The raw density profile is used as input to the combined model to calculate the precipitation production rate, and the concentration of the 55 most relevant ions that may be taking part in the chemical reactions defining the equilibrium electron concentration (see Turunen, 1996; Burns et al., 1991; Turunen et al., 1992). This also allows the determination of the theoretical ACF, which is consistent with these ion concentrations, and will be compared with the radar observations. The negative ion-chemistry of the D-region can thus be studied, in particular the effects of photodetachment and photodissociation at the sunset transition. 


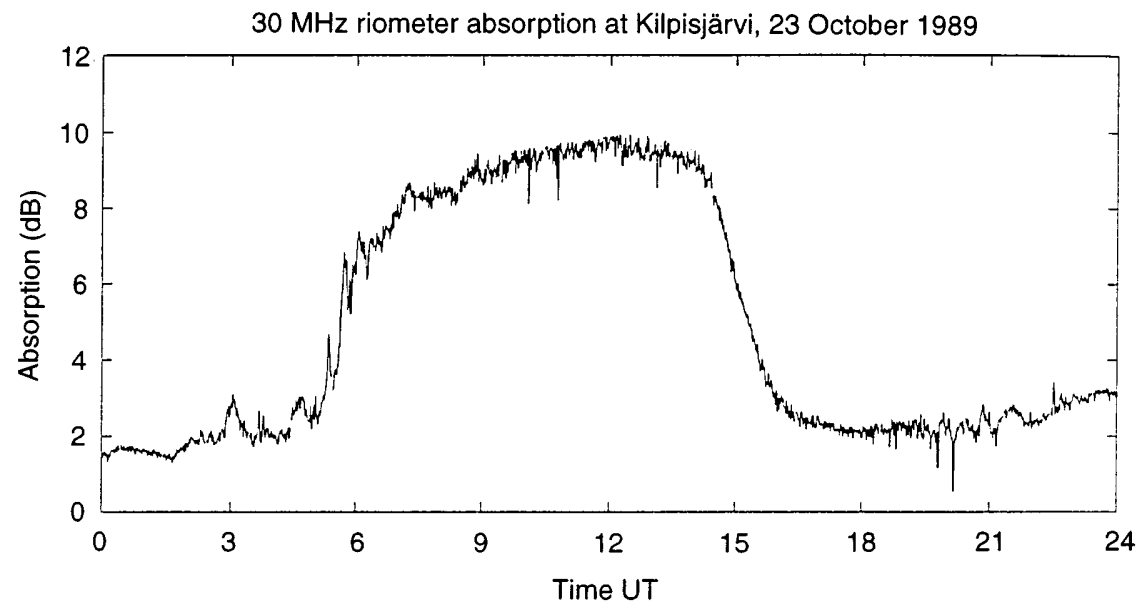

Fig. 1. Riometer absorption at $30 \mathrm{MHz}$ measured at Kilpisjärvi during the PCA event on 23 October, 1989
In Sect. 2 we present the observations around the sunset transition on October 23, 1989 discussed in this work, in Sect. 3 we briefly introduce the combined model applied in the interpretation of the measured $\mathrm{ACF}$, and in Sect. 4 we discuss our results. Section 5 provides a summary and conclusion of the study.

\section{Observations}

Incoherent scatter radars measure the plasma ACF associated with the spectrum of the ion-acoustic fluctuations in the ionosphere, at wave-number $k=4 \pi / \lambda_{R}\left(\lambda_{R}\right.$ is the radar wavelength). At mesospheric heights the spectrum is very narrow and some special observing techniques need to be implemented: GEN11 is a pulse-to-pulse algorithm using double 13-bit Barker code scheme with subpulse length of $7 \mu$ s for range resolution $1.05 \mathrm{~km}$ (Turunen, 1986), and it determines the ACF over 42 range gates with 21 lags per gate plus an estimate of the power profile (the pseudo zero-lag). Some range ambiguity introduced by the code can be satisfactorily corrected in most cases (Pollari et al., 1989). The code is used on both EISCAT UHF and VHF radars with, typically, lag separations $\left(\tau_{\mathrm{lag}}\right)$ of $2.22 \mathrm{~ms}$ and $3.23 \mathrm{~ms}$, respectively. The frequency window probed by the radars is defined by the Nyquist frequency (maximum width $\Delta f_{\max }=$ $2 f_{\text {Nyquist }}=1 / \tau_{\text {lag }}$ ), and the fundamental frequency $\left(\Delta f_{\min }=2 f_{\mathrm{o}}=1 /\left(21 \times \tau_{\mathrm{lag}}\right)\right):$ this corresponds to the range $22 \mathrm{~Hz} \leq \Delta f \leq 450 \mathrm{~Hz}$ for our UHF observations at $2.22 \mathrm{~ms}$.

Below $80 \mathrm{~km}$ altitude the raw density $N_{e}^{\text {raw }}$ is a function of both the actual density $n_{\mathrm{o}}$ and the total concentration of negative ions (Mathews, 1978). This dependence is given by

$N_{e}^{\text {raw }}=\frac{2 n_{\mathrm{o}}(1+2 \lambda)}{\left(1+\alpha^{2}\right)\left[1+\alpha^{2}+\left(1+2 \lambda_{-}\right) T_{e} / T_{i}\right]}$

In the last equation, $\alpha^{2}=(6.9 \times 4 \pi / 32)^{2}\left(T_{e} / n_{\mathrm{o}}\right)\left(T_{e}\right.$ in $\mathrm{K}$ and $n_{\mathrm{o}}$ in $\left.\mathrm{cm}^{-3}\right)$ is the Debye-length term, and $\lambda_{-}$is the ratio of the total negative-ion concentration to the electron density. Figure 2 displays the raw electron density profiles (in $\mathrm{m}^{-3}$ ) measured during the sunset transition on 23 October 1989, and in the presence of a strong proton precipitation event. They correspond to a number of selected profiles (averaged over $10 \mathrm{~min}$ ) between 1330 and 1520 UT for solar zenith angles between $87^{\circ}$ and $95^{\circ}$. Figure 3 displays the observed spectral widths corresponding to the periods shown in Fig. 2, the widths were obtained from the correlation time of the ion component of the measured plasma autocorrelation functions. Figure 4, for the same periods as Figs. 2 and 3, shows the 'true' electron density profiles obtained by combining the Sodankylä model and the observed pseudo-zero lag (raw density) profile.

\subsection{Theoretical spectral width}

In the lower ionosphere it is generally a good approximation to calculate the spectrum of the ion-acoustic fluctuations using the BGK-collisional limit (see Dougherty and Farley, 1963; Mathews, 1978). Binary collisions between ions and neutrals are dominant and the ion plasma function may be replaced by its large argument approximation, this leads to a simple analytical expression for the spectral function (Fukuyama and Kofman, 1980):

$$
\begin{aligned}
S_{i}(k, \omega)= & \frac{2 n_{\mathrm{o}}\left(1+2 \lambda_{-}\right)}{\pi\left(1+\alpha^{2}\right)\left[1+\alpha^{2}+\left(1+2 \lambda_{-}\right) T_{e} / T_{i}\right]} \\
& \times \frac{\Delta \omega}{\left(\omega-\omega_{\mathrm{o}}\right)^{2}+\Delta \omega^{2}},
\end{aligned}
$$

where $\omega_{\mathrm{o}}=k \cdot V_{n}$ ( $V_{n}$ is the neutral wind's velocity) and $\Delta \omega$ is the Lorentzian half-width. The total width $\Delta f$ is thus,

$\Delta f=\frac{k_{\|}^{2} V_{i}^{2}}{2 \pi v_{\text {in }}}\left[1+\alpha^{2}+\frac{T_{e}}{T_{i}}\left(1+2 \lambda_{-}\right)\right] \frac{1}{1+\alpha^{2}}$

$V_{i}$ is the ions' thermal velocity and $k_{\|}=k \cos (\mathrm{ANG})$ (ANG is the angle between the magnetic field line and the radar line-of-sight). We have assumed that the ionneutral collision frequency is given by, 


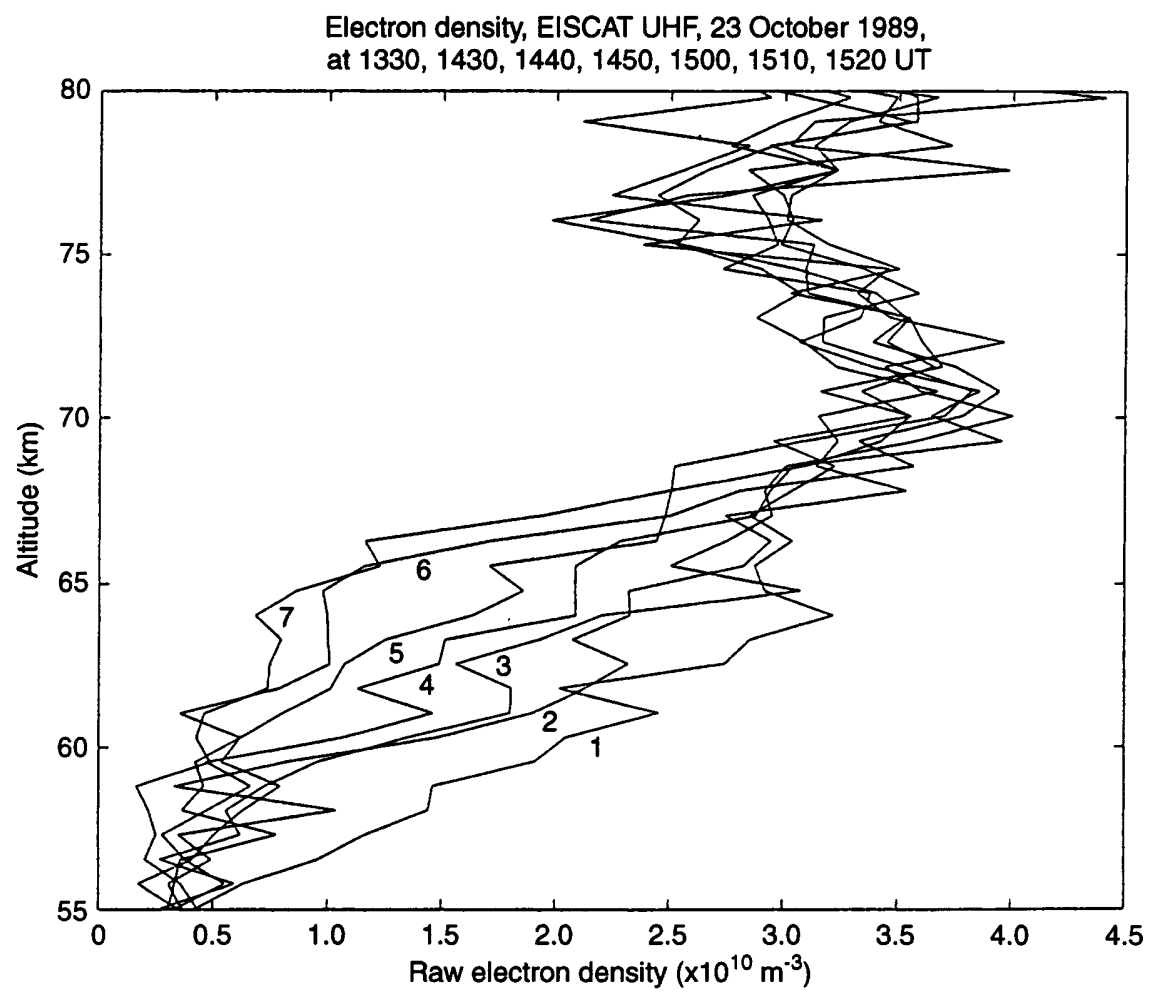

Fig. 2. Raw electron density profiles (in $\mathrm{m}^{-3}$ ) from EISCAT measurements of the proton precipitation event during sunset on 23 October, 1989. The numbers on the curves identify, in increasing order, the zenith angles (and UT) of the individual determinations: $87.1^{\circ}(1330), 91.1^{\circ}(1430), 91.9^{\circ}(1440), 92.6^{\circ}$ (1450), $93.4^{\circ}(1500), 94.2^{\circ}(1510)$, and $95.1^{\circ}$ (1520)

$$
\begin{aligned}
v_{\text {in }}\left(\mathrm{s}^{-1}\right)=2.6 & \times 10^{-9} \frac{n_{n}\left(\mathrm{~cm}^{-3}\right)}{\sqrt{M_{i}(\mathrm{amu})}}\left[1.03 \times \sqrt{\frac{m N_{2}}{M_{i}+m_{\mathrm{N}_{2}}}}\right. \\
& \left.+0.28 \times \sqrt{\frac{m_{\mathrm{O}_{2}}}{M_{i}+m_{\mathrm{O}_{2}}}}\right]
\end{aligned}
$$

where $n_{n}$ is the total neutral concentration, $M_{i}$ is the average positive ion mass, and $m_{\mathrm{N}_{2}, \mathrm{O}_{2}}$ are the masses of $\mathrm{N}_{2}$ and $\mathrm{O}_{2}$ in atomic mass units. We have also calculated the width of the ion-acoustic spectrum using the full plasma function and, as expected, it is in very good agreement with the collisional limit.

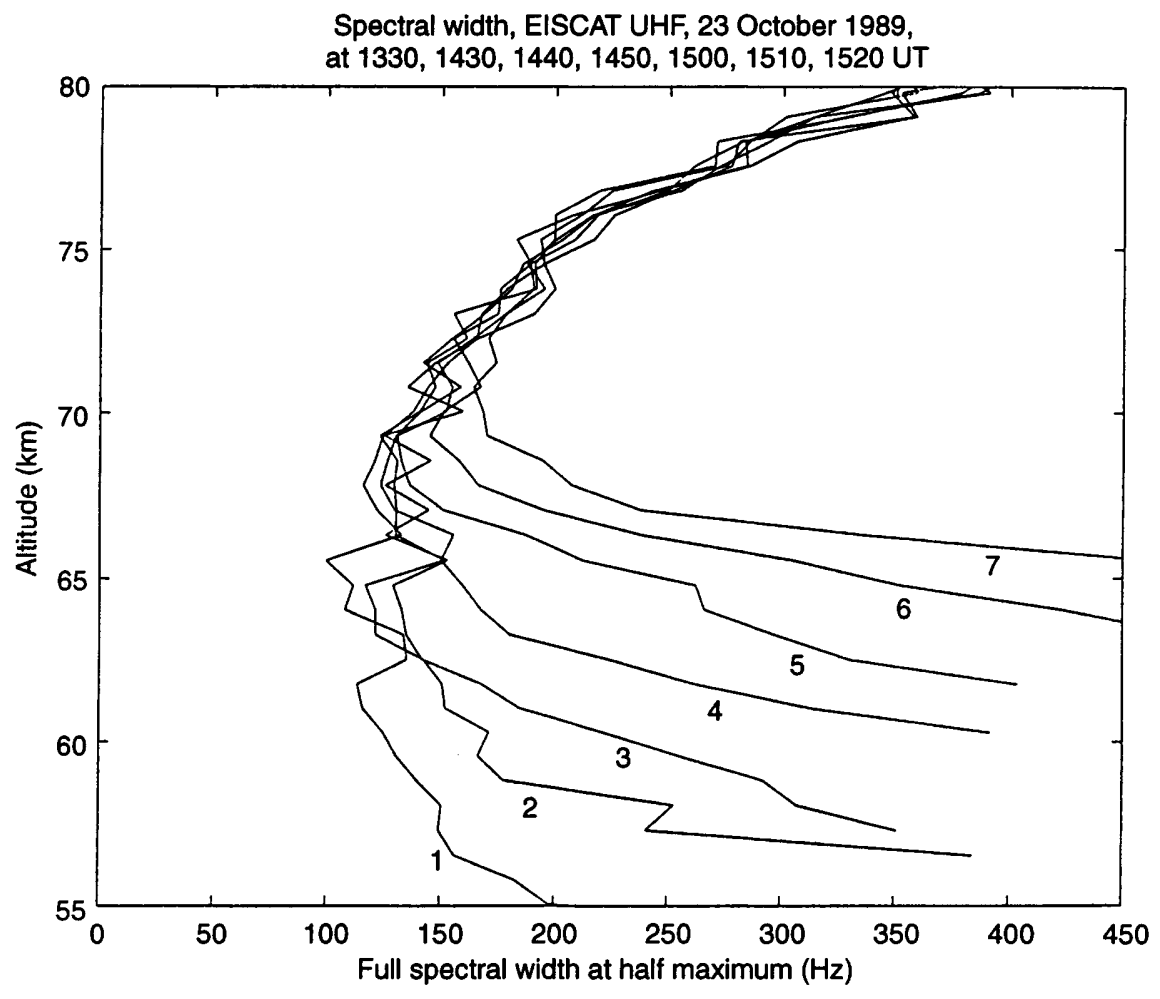

Fig. 3. Width of the spectra of the ionacoustic fluctuations at the various heights and times of the event shown in Fig. 1. The widths are given in $\mathrm{Hz}$ in the $55-80 \mathrm{~km}$ altitude range. They were directly obtained from the correlation time of the plasma autocorrelation functions (ACF) measured by the UHF radar applying the GEN11 code 
SIC model, PCA event, 23 October 1989, at $1330,1430,1440,1450,1500,1510,1520$ UT

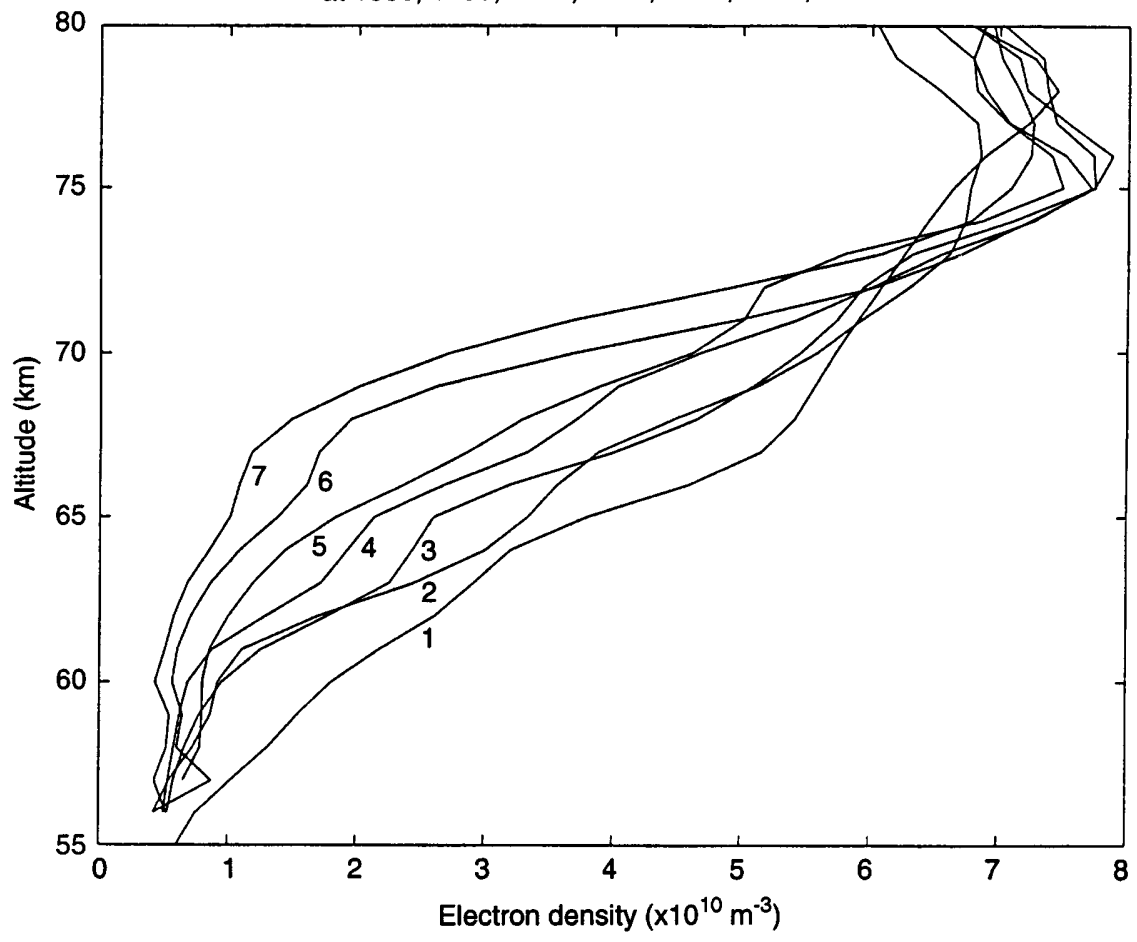

Fig. 4. Electron densities (in $\mathrm{m}^{-3}$ ) after correction of the Debye length, and the negative ion-ratio dependences on the 'raw' density profiles (shown in Fig. 1). The resulting profiles have been smoothed over $2 \mathrm{~km}$ in altitude

\section{The combined model}

This is a model of the disturbed $\mathrm{D}$ and $\mathrm{E}$ regions which combines the Sodankylä Ion Chemistry Model with a procedure to estimate the precipitation production rate, and particle spectrum by inverting the measured electron density profiles. The model assumes chemical equilibrium and in-situ charge neutralisation below $\sim 120 \mathrm{~km}$, because the recombination processes ensure that the chemical lifetimes of the ions are short with respect to changes due to transport processes (Brasseur and Solomon 1986). We are thus using the steady state approximation. We may, in fact, neglect the changes in the electron density at integration times of the order of, or greater than, the recombination time (see Appendix).

The model includes 55 ions (36 positive and 19 negative) and the reactions likely to occur between them (see Turunen, 1996; Turunen et al., 1992; Burns et al., 1991). In addition to the five main positive ions in the $D$ and $\mathrm{E}$ regions $\left(\mathrm{O}^{+}, \mathrm{O}_{2}^{+}, \mathrm{N}_{2}^{+}, \mathrm{NO}^{+}\right.$, and $\left.\mathrm{O}_{4}^{+}\right)$, it includes 19 negative ions $\left(\mathrm{O}^{-}, \mathrm{O}_{2}^{-}, \mathrm{O}_{3}^{-}, \mathrm{O}_{4}^{-}, \mathrm{OH}^{-}, \mathrm{CO}_{3}^{-}, \mathrm{CO}_{4}^{-}\right.$, $\mathrm{NO}_{2}^{-}, \mathrm{NO}_{3}^{-}$, and its excited state $\mathrm{NO}_{3}^{*-}, \mathrm{HCO}_{3}^{-}$, chloride ions $\mathrm{Cl}^{-}$and $\mathrm{ClO}^{-}$, the first-order hydrates of $\mathrm{NO}_{3}^{-}$, $\mathrm{CO}_{3}^{-}, \mathrm{O}_{2}^{-}, \mathrm{O}_{3}^{-}, \mathrm{OH}^{-}$, and $\left.\mathrm{Cl}^{-}\right)$, proton hydrates $\left(\left(\mathrm{H}_{2} \mathrm{O}\right)_{\mathrm{n}} \mathrm{H}^{+}, \mathrm{n}=1\right.$ to 8$), \mathrm{NO}^{+}$hydrates (up to the third order, and $\left(\mathrm{H}_{2} \mathrm{O}\right)_{\mathrm{n}} \mathrm{N}_{2} \mathrm{NO}^{+},\left(\mathrm{H}_{2} \mathrm{O}\right)_{n} \mathrm{CO}_{2} \mathrm{NO}^{+}$, for $\mathrm{n}=1$, 2 ), and other cluster ions involving further clustering between the previous ions and other minor constituents $\mathrm{CO}_{2}, \mathrm{OH}, \mathrm{HO}_{2}$ ).

Figure 5 displays the block-diagrams for the chemical reactions between the 36 positive ions in the model (Fig. 5a), and between the 19 negative ions (Fig. 5b). The various ions in the blocks are either the start or the final products of the reactions sketched by the connecting arrows (labelled with the basic neutral 'raw material', or identifying the three body reaction with a generic $M$ component). The solid line blocks in both diagrams show the reactions in the original 37-ion (26 positive and 11 negative) Sodankylä Ion Chemistry model.

The model uses the MSIS90 reference neutral atmosphere for the temperatures $T_{n}=T_{i}=T_{e}$ and the concentrations of $\mathrm{N}_{2}, \mathrm{O}_{2}, \mathrm{O}, \mathrm{H}, \mathrm{Ar}, \mathrm{He}$ and $\mathrm{N}$. The model also considers fixed concentration profiles for the other minor constituents such as, $\mathrm{O}_{3}, \mathrm{CO}_{2}, \mathrm{OH}, \mathrm{NO}_{2}, \mathrm{NO}$, $\mathrm{H}_{2} \mathrm{O}, \mathrm{HO}_{2}$ and $\mathrm{O}_{2}\left({ }^{1} \Delta \mathrm{g}\right)$, based on the values given by Shimazaki (1985). At each step the model calculates the production rate due to solar radiation and cosmic rays, using reactions rates and the measured cross sections for the absorption and ionisation processes from the recent literature (see Turunen, 1996, and references therein). At high latitudes, particularly at night, the main source of ionisation is the precipitation of energetic particles of solar and magnetospheric origin. The incoming particles ionise the atmospheric constituents $\left(\mathrm{O}_{2}, \mathrm{~N}_{2}, \mathrm{O}, \mathrm{He}, \mathrm{N}\right)$, producing secondary electrons which are equivalent to the photoelectrons produced by solar radiation and the total production rate is simply the sum of the pair production rates due to particle precipitation, solar radiation and cosmic-rays. The rate of collisional ionisation between neutrals and the flux of monoenergetic electrons or ions is calculated using the framework presented by Rees (1989).

An additional source of ionisation, which is of particular importance for normal conditions (without particle precipitation), at night and during sunset and 

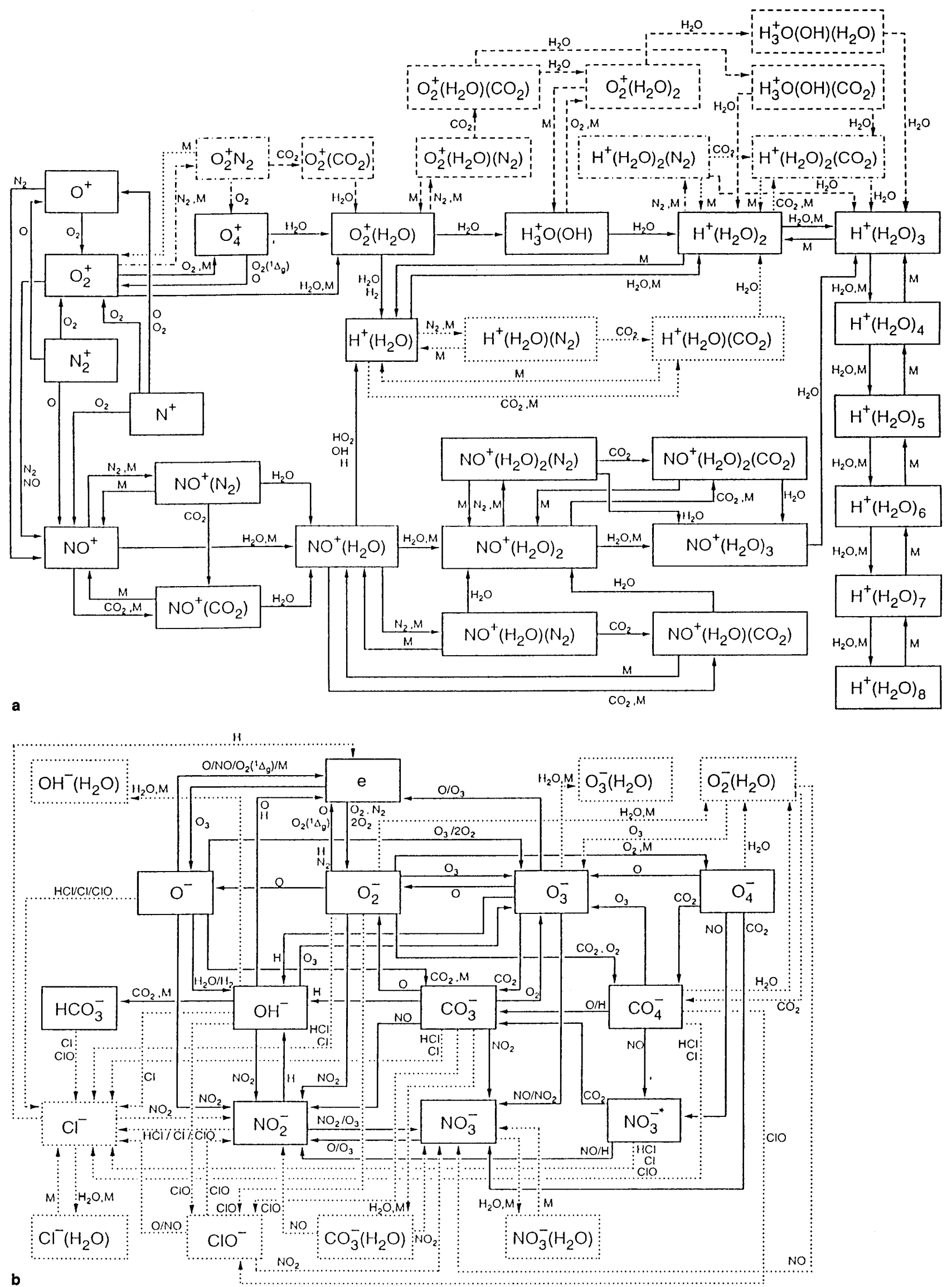
sunrise transitions, is the scattered or diffuse component of the solar ultraviolet flux at the Lyman- $\alpha$ and $\beta$ lines (at $121.6 \mathrm{~nm}$ and $102.6 \mathrm{~nm}$ ). These are included in the model using the empirical approximations given by Thomas and Bowman (1986), for instance for the scattered Lyman- $\alpha$ :

$$
\begin{aligned}
F_{L y-\alpha}= & 1.5 \times \frac{F_{\mathrm{o} L y-\alpha}}{\left(0.1+\cos ^{2} \chi\right)} \\
& \times \exp [-0.48(\exp (0.15(85.0-h))-1.0)]
\end{aligned}
$$

$F_{\mathrm{oLy}-\alpha}$ is the solar flux at the top of the ionosphere, $\chi$ is the zenith angle, $h$ is the height in $\mathrm{km}$, and the fluxes are given in $\mathrm{cm}^{-2} \mathrm{~s}^{-1}$.

In our case where there is a strong PCA, the proton precipitation totally dominates the ion production. However, photochemistry is important to the ionisation balance, since the photochemical reactions need sunlight to be effective. In order to better represent the gradual change of spectral width at sunset, we have assumed a zenith angle dependence in the effective reaction cross sections of both the photodetachment and photodissociation processes. We have 'scaled' them by a factor equal to the ratio of the integrated solar flux, at the corresponding height and zenith angle, to its noon value of $50 \mathrm{~km}$.

Figure $6 \mathrm{a}-\mathrm{c}$ shows the observed spectral widths (solid lines) together with the theoretical results at three selected times around sunset: 1430 (zenith angle $91.1^{\circ}$ ), 1500 (zenith angle $93.5^{\circ}$ ), and 1520 UT (zenith angle $95.1^{\circ}$ ). Dashed lines identify the full plasma calculation, and dotted lines the collisional approximation (given by Eq. 3).

\section{Discussion}

The chemistry of the E region (above $95 \mathrm{~km}$ ) is relatively simple, and the ion composition is fairly uniform and dominated by the presence of $\mathrm{O}_{2}^{+}$and $\mathrm{NO}^{+}$ions. This is not the case in the mesosphere (D region), particularly at night, where cluster and negative ions exert a controlling influence over the variations in the electron density. The transition between the region dominated by the simpler molecular ions and that of the cluster and hydrated ions varies from about 70 to $90 \mathrm{~km}$ according to season, latitude and intensity of particle precipitation

Fig. 5a, b. Block-diagrams for the chemical reactions involving positive and negative ions in the Sodankylä model. a It involves the 36 positive ions in the model. We may identify four major reaction channels, the first involving the molecular ions $\left(\mathrm{O}^{+}, \mathrm{O}_{2}^{+}, \mathrm{N}_{2}^{+}, \mathrm{NO}^{+}\right.$, and $\left.\mathrm{O}_{4}^{+}\right)$, the second associated with the proton hydration process $\left(\mathrm{H}^{+}\left(\mathrm{H}_{2} \mathrm{O}\right)_{\mathrm{n}}, \mathrm{n}=1\right.$ to 8$)$, the third with the NO hydration process, and the fourth involving further clustering between the ions and other minor constituents $\left(\mathrm{CO}_{2}, \mathrm{OH}, \mathrm{HO}_{2}\right)$. b It involves the 19 negative ions in the model. Negative ions are initially formed by the attachment of electrons to molecular oxygen, and then through reactions involving other minor constituents (water vapour, nitric oxide, nitric and carbon dioxides, and chloride)
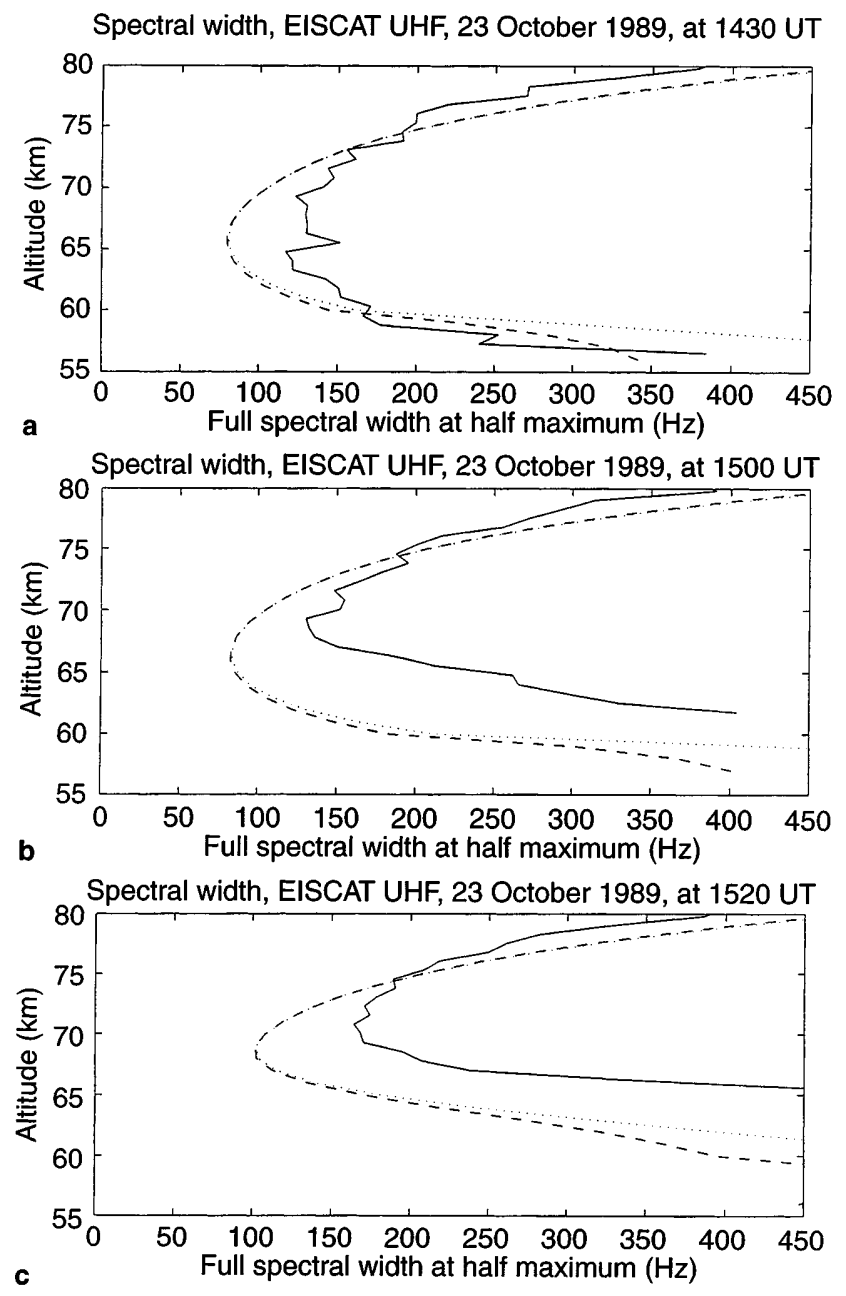

Fig. 6a-c. Observed spectral widths as functions of height (solid lines), and model results for full plasma calculation (dashed lines) and collisional approximation (dotted lines). a For 1430 UT, b for 1500 UT, and $\mathbf{c}$ for 1520 UT. See text for zenith angle dependence of the assumed photodetachment and photodissociation rates

(Brasseur and Solomon, 1986). This transition is extremely sensitive to changes in the lower boundary of ionisation due to the very dynamic nature of the precipitation. Negative ions, on the other hand are dominant in the lower mesosphere.

During the day, and below $65 \mathrm{~km}$, the electron density is generally smaller than the total negative-ion concentration by a factor between 10 and 100 , but at night this only happens below $75 \mathrm{~km}$. The transition zone between electrons and negative ions appears to be located near $70 \mathrm{~km}$ during the day, and 5 to $10 \mathrm{~km}$ higher at night (see e.g. Brasseur and Solomon, 1986). In our case of strong PCA, the altitude of the transition to negative ions is $5 \mathrm{~km}$ lower. Precipitation increases the relative abundance of the simpler, molecular ions as well as the electron density (electrons recombine faster with the clusters). Harder particle precipitation penetrating below $75 \mathrm{~km}$ also affects the abundance of negative ions by enhancing recombination and charge neutralisation. Even if precipitation may increase the electron attachment by increasing the electron density, the increase in 
the recombination of negative ions with positive ions is expected to be dominant. Thus the ratio of the negativeion concentration to the electron density would decrease with increasing production. During daytime too, photochemical processes reduce the abundance of cluster and negative ions, and the simpler molecular ions become dominant.

Figure 7a displays the ratio of the total negative ion concentration to the electron density as a function of height for the same model runs shown in Fig. 4. We notice the importance of the photo-chemical processes on the destruction of negative ions during the sunset transition. Photodetachment of electrons from the negative ions, and to a lesser extent, photodissociation, are the basic processes for the destruction of negative ions during the sunset transition. To stress the impor-

SIC model, 23 October 1989 ,

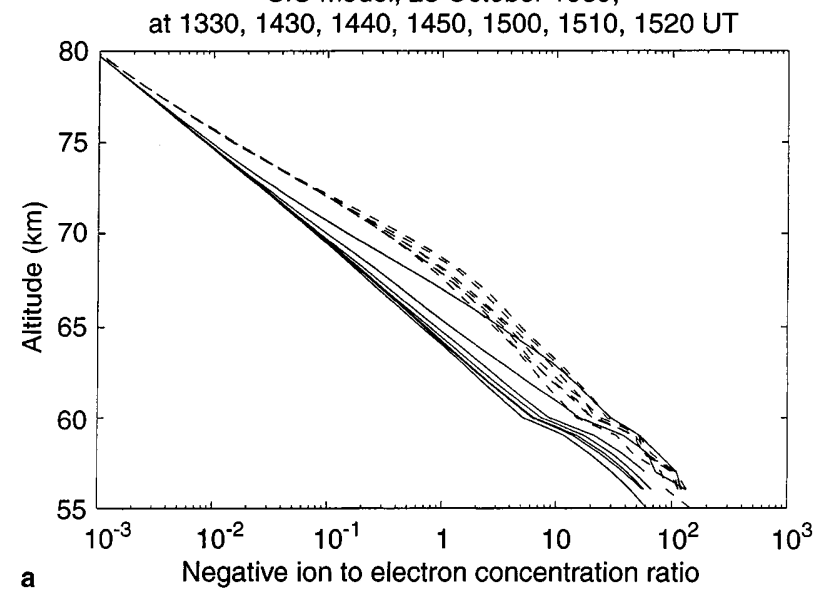

PCA events on 14 August (from Turunen, 1993) and 23 October 1989

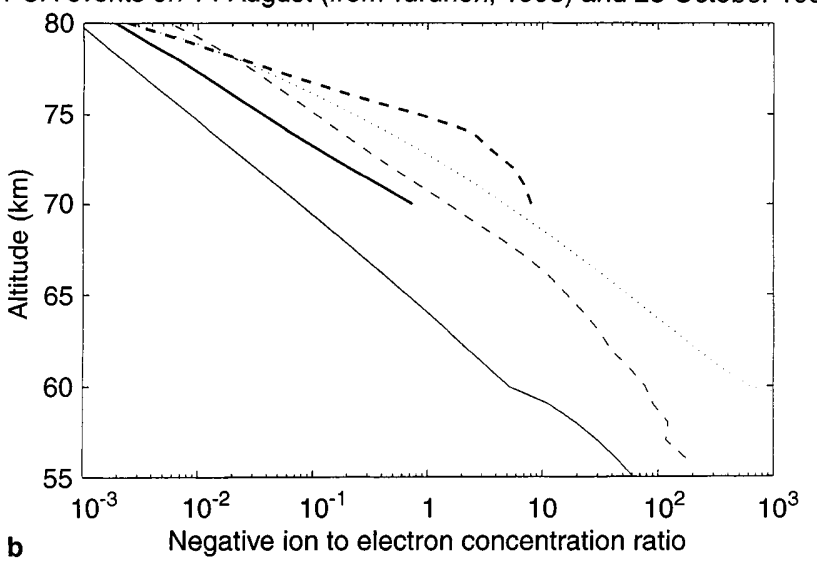

Fig. 7. a Height profiles of the total negative-ion ratio, $\lambda_{-}$, corresponding to Fig. 3. To stress the importance of photodetachment we display together the results from the full model calculations (solid lines), and the results without photodetachment and photodissociation (dashed lines). For practical reasons the lines are not numbered, the zenith angle increases in the curves from left to right. b Total negative-ion ratio for 23 October, 1989, at 1330 UT (thin solid line) and 1520 UT (thin dashed line), together with results for 14 August, 1989 (Turunen, 1993) at 0255 UT (thick solid line) and 0005 UT (thick dashed line). Note that the PCA event in August was weaker than in October. Also shown for comparison is the result without ionisation by protons, for 23 October at 1520 UT (dotted line) tance of photodetachment we display together the results from the previously described model calculations (solid lines), and the results without photodetachment and photodissociation (dashed lines). For practical reasons the lines are not numbered. The zenith angle is increasing with the curves from left to right, the assumed equilibrium concentrations of the minor constituents were the same for all the calculations.

Similar calculations of the ratio, $\lambda_{-}$, of the total negative ion concentration to the electron density were performed by Turunen (1993) for a PCA event on 14 August, 1989. Figure 7b displays together our model results with those given by Turunen (1993), it shows the ratio $\lambda_{-}$for the two periods (23 October 1989 , and 14 August, 1989) at two pairs of similar zenith angles. For 23 October the thin solid line gives the ratio at zenith angle $87.1^{\circ}(1330 \mathrm{UT})$ and the thin dashed line at $95.1^{\circ}$ (1520 UT), for 14 August the thick solid line gives the ratio at $86.0^{\circ}(0255 \mathrm{UT})$ and the thick dashed line at $95.0^{\circ}$ (0005 UT). For comparison, we have also added an altitude profile of the ratio of the total negative ion concentration to the electron density during quiet night conditions (dotted line), by switching off the ion production by the proton precipitation. As it can be seen the ratios from the two periods are different, for similar zenith angles. The PCA event of 14 August was however much weaker, the flux of protons at energies $>10 \mathrm{MeV}$ was an order of magnitude less than for the October event (see e.g. Ranta et al., 1993). This means that in August the negative ion concentration was higher and the electron density weaker, and consequently the ratio $\lambda_{-}$was, for the same height, greater for the August event than for the October event.

Under quiet conditions, most of the ionisation in the $D$ region is due to the effect of the solar Lyman- $\alpha$ flux on NO. Even at night when the direct incident flux is zero, there is still a considerable flux of scattered Lyman- $\alpha$ radiation reflected by the hydrogen geocorona at all levels of the atmosphere. Equilibrium ion composition in the $\mathrm{D}$ region is, therefore, closely related to the distribution of $\mathrm{NO}$, which is strongly tied to dynamics. Nitric oxide is produced in large amounts in the stratosphere and thermosphere and then transported into the mesosphere in a time scale of a few days. In our case of a strong PCA, with large changes in ionisation over a period of a few hours, the concentration of NO is not, in any way, the most important source of ionisation but it appears to be important for the chemical balance in the region where negative ions are dominant. This is also true for other minor constituents like atomic oxygen and ozone.

\subsection{Derivative of the spectral width with the neutral densities}

The measured spectral width is seen to undergo significant variations during sunset. Qualitatively, one could argue that what is happening is the formation of negative ions when the amount of direct solar radiation diminishes and the rate of photodetachment of electrons 
decreases. Moreover, the destruction of negative ions through both photodetachment (of mainly $\mathrm{O}^{-}, \mathrm{O}_{2}^{-}, \mathrm{O}_{3}^{-}$, $\mathrm{OH}^{-}, \mathrm{NO}_{3}^{-}, \mathrm{CO}_{3}^{-}, \mathrm{NO}_{2}^{-}$) and photodissociation (of mainly $\mathrm{O}_{3}^{-}, \mathrm{O}_{4}^{-}, \mathrm{CO}_{3}^{-}, \mathrm{CO}_{4}^{-}$) is substantially reduced at sunset and switched-off at night. To check this quantitatively using our combined model, first of all we scaled the photochemical reaction rates to follow the change in the solar production rate with zenith angle (as described in the paragraph on the combined model), but the concentrations of the minor neutral constituents were unchanged. This approach could not explain the observed variations in the spectral width as shown in Fig. 6.

The next step was to look at the effects in the spectral width of varying the concentrations of the minor neutral constituents. We may, indeed, expect significant changes in the concentration of some of these constituents, particularly during sunset and lower altitudes (see Shimazaki, 1985, and references therein). In order to estimate the extent of such effects we calculate the partial derivatives of the spectral width with respect to the concentration of each minor constituent. The derivatives can then be compared with each other by multiplying each derivative by the concentration of the corresponding constituent. This is equivalent to assume that each of the concentrations is known to some relative accuracy. Then the small variations by a fixed percentage would yield, in the first approximation, a corresponding change in spectral width, which is the sum of the scaled derivatives multiplied by the percentage.

Practically no variation of spectral width is seen for small changes in the concentrations of $\mathrm{H}_{2} \mathrm{O}, \mathrm{HO}_{2}, \mathrm{NO}_{2}$, $\mathrm{CO}_{2}, \mathrm{OH}, \mathrm{H}, \mathrm{N}, \mathrm{He}$ and Ar. The largest effect is, in fact, achieved by modifying the temperature. Other than affecting the reaction rates, it also induces changes in the various neutral densities, and thus in the spectral width. A similar large effect is produced by the direct variations in the concentrations of the major constituents $\mathrm{N}_{2}$ and $\mathrm{O}_{2}$, which affect the spectral width largely through the collision frequency. Changes in the concentration of the minor constituents $\mathrm{O}, \mathrm{NO}, \mathrm{O}_{3}$, and $\mathrm{O}_{2}\left({ }^{1} \Delta \mathrm{g}\right)$, affect the chemical balance and, indirectly, the spectral width by changing the total negative ion concentration and the average positive ion mass.

The scaled derivatives are compared in Fig. 8. As we can see, the changes in the density of $\mathrm{N}_{2}$ and $\mathrm{O}_{2}$ are seen to affect the whole altitude range measured by EISCAT, whereas changes in $\mathrm{O}, \mathrm{NO}$, and in a lesser extent $\mathrm{O}_{3}$, $\mathrm{O}_{2}\left({ }^{1} \Delta \mathrm{g}\right)$, are effective only at lower altitudes, below $65 \mathrm{~km}$. The relative changes of spectral width produced by the variations in the concentration of $\mathrm{O}$ and $\mathrm{NO}$ appear to be of the same order (also the effects of $\mathrm{O}_{3}$ and $\mathrm{O}_{2}\left({ }^{1} \Delta \mathrm{g}\right)$ are comparable), so it may be difficult to separate their various effects based on our model calculations alone. We know, however, that the concentration of NO must not experience any significant change at the time scale discussed here (of 1 to $2 \mathrm{~h}$ ). Changes in the concentration of NO strongly affect the negative ion chemistry since the concentration of the derived ions $\mathrm{NO}_{2}^{-}$and $\mathrm{NO}_{3}^{-}$(and its hydrates) are among the most abundant end products at chemical

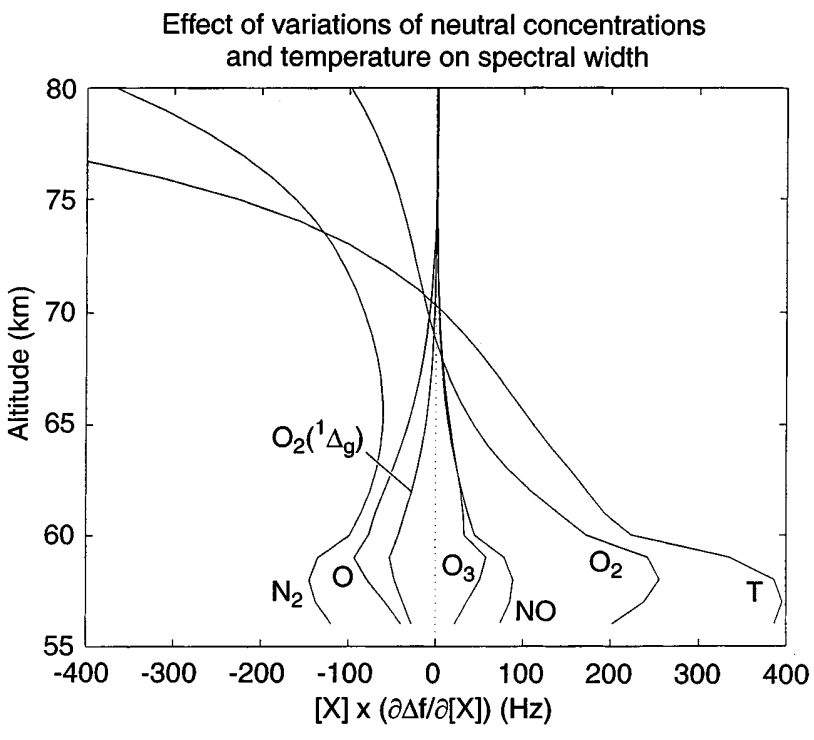

Fig. 8. Effects on the spectral width from changes in the concentration of various neutral constituents, and in the neutral temperature. The plot shows the scaled partial derivatives of spectral width with respect to the concentrations of some relevant constituents, as well as the temperature. Each derivative has been multiplied by the concentration of the corresponding constituent, or by the temperature

equilibrium. On the other hand, changes in the concentration of atomic oxygen may indeed explain the variation of the spectral width in these conditions. Its concentration below $\sim 80 \mathrm{~km}$ is expected to drop by several orders of magnitude during sunset (Ogawa and Shimazaki, 1975; Shimazaki, 1985).

Atomic oxygen as well as ozone, and $\mathrm{O}_{2}\left({ }^{1} \Delta \mathrm{g}\right)$, takes part in a number of crucial negative ion reactions. In the mesosphere the lifetime of $\mathrm{O}$ is of the order of one to a few hours and that of $\mathrm{O}_{3}$ of the order of minutes, and thus substantial changes in their densities are possible in the time scale of interest. Evidence of large changes in $[\mathrm{O}]$ have been presented (see Chakrabarty and Ganguly, 1989, and references therein), but large changes in ozone in similar conditions has not been reported so far. Energetic protons do indeed ionise $\mathrm{O}_{3}$ but during this PCA event there is no evidence of sudden changes in the precipitation flux around sunset that may justify the radical reduction in $\left[\mathrm{O}_{3}\right]$ needed to explain the changes in the total negative ion concentration we observe. On the other hand, as in the case of atomic oxygen, the concentration of $\mathrm{O}_{2}\left({ }^{1} \Delta \mathrm{g}\right)$ is expected to drop radically at night in the lower heights. Further, the lifetime of $\mathrm{O}_{2}\left({ }^{1} \Delta \mathrm{g}\right)$ is never more than its radiative lifetime of about 1 hour. We may conclude that changes in [O], and in a lesser extent $\left[\mathrm{O}_{2}\left({ }^{1} \Delta \mathrm{g}\right)\right]$, could well explain the observed changes in the total negative-ion concentration at the sunset/night transition.

Atomic oxygen plays an important role in the definition of the equilibrium concentration of the various relevant negative ions. It is involved in the reactions controlling, and mainly reducing, the concentrations of ions such as $\mathrm{O}_{1}^{-}, \mathrm{O}_{2}^{-}, \mathrm{O}_{3}^{-}, \mathrm{O}_{4}^{-}, \mathrm{OH}^{-}, \mathrm{NO}_{3}^{-}, \mathrm{CO}_{3}^{-}, \mathrm{NO}_{2}^{-}$, and $\mathrm{CO}_{4}^{-}\left(\mathrm{O}_{2}\left({ }^{1} \Delta \mathrm{g}\right)\right.$ is involved in reactions reducing the concentration of $\mathrm{O}^{-}$and $\mathrm{O}_{2}^{-}$). This is the reason why a 
sizeable reduction in, basically, [O] may radically increase the total amount of negative ions and, thus, to broaden the ion-line. The derivative of the width with respect to the concentrations, presented in Fig. 8, give us an indication of how much we need to change the concentration of atomic oxygen at each height to obtain a closer match between the measured and the calculated spectral widths.

\subsection{Changing the neutral temperature and the concentration of atomic oxygen}

Since there are too many degrees of freedom in selecting the possible variations in the various minor constituents, we will not try to achieve an exact match between the measured spectral widths and the model calculations. Instead we will estimate by how much we need to 'adjust' the two main parameters identified in the previous paragraphs $([\mathrm{O}]$ and neutral temperature) in order to produce a general agreement with the observations. Let us, therefore, vary the neutral temperature and the concentration of atomic oxygen by some reasonable amounts, within the ranges of their expected and/or observed variability during similar geophysical conditions.

Figure 9 shows the effect of these variations in the calculated spectral width, superimposed to the radar measurements. In Fig. 9a, the temperature was modified $\pm 20 \mathrm{~K}$ from the MSIS 90 reference value. Comparison with the experimental spectral width (solid line) at 1430 UT shows that increasing the temperature (dashed line) greatly improves the fit above $75 \mathrm{~km}$, whereas below $60 \mathrm{~km}$ a better match is achieved by decreasing it (dotted line). In the $65-70 \mathrm{~km}$ altitude range, however, no reasonable change in temperature seems to make the model and experimental spectral widths to agree. A reduction in the assumed concentrations of $\mathrm{NO}$ or $\mathrm{O}$ at these heights may indeed improve the match.

Figure $9 \mathrm{~b}$ shows the measured (solid line) and the calculated spectral widths at 1520 UT, using two different altitude profiles of atomic oxygen, one for normal daytime conditions (dashed line) and one for the concentration of atomic oxygen divided by factor of ten (dash-dotted line). We may see that at $1520 \mathrm{UT}$, for zenith angle of $95.1^{\circ}$, we obtain a very good agreement between the calculated and the measured widths when the decreased value, $[\mathrm{O}] / 10$, is used in the calculations. As we mentioned before, the concentration of atomic oxygen is expected to decrease substantially at the sunset transition (Ogawa and Shimazaki, 1975).

Clearly, the model could allow the estimation of the concentration of atomic oxygen from the spectral width, if the concentrations of the other minor constituents and the temperature are known. Moreover, the gradual but substantial reduction in $[\mathrm{O}]$ around sunset may also help to understand the solar zenith angle dependence in the measured spectral width. This may partly explain the result of Fig. 6 in which the scaling of the photochemical reaction rates, as a function of this zenith angle, is not enough to reproduce the changes observed.
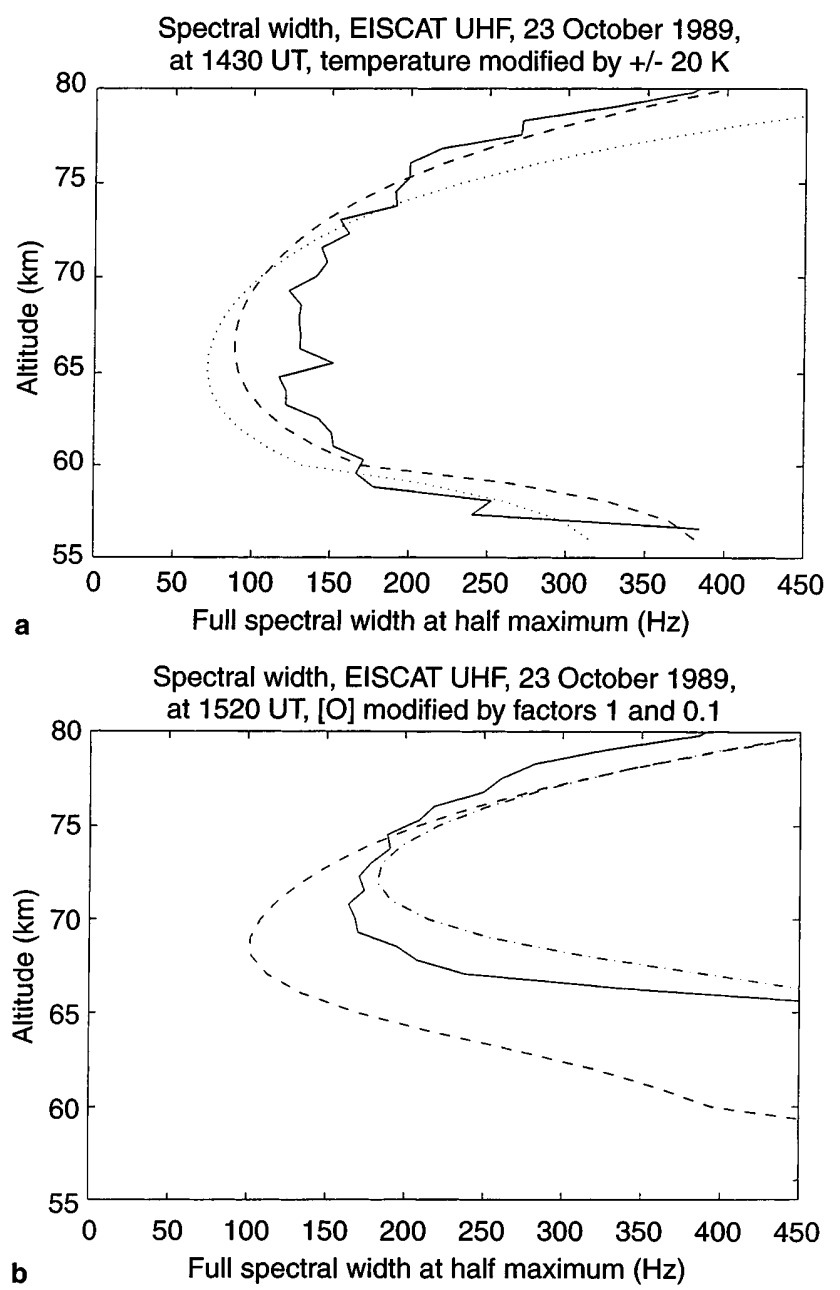

Fig. 9a, b. The effect of variations in temperature a and in concentration of atomic oxygen $\mathbf{b}$ on the spectral width at 1430 UT and 1520 UT, respectively, on 23 October 1989. In a the temperature was varied by $+20 \mathrm{~K}$ (dashed line) and by $-20 \mathrm{~K}$ (dotted line) from the value given by MSIS90. The solid line is the experimental data. In $\mathbf{b}$ the daytime concentration of atomic oxygen (corresponding spectral width given by dotted line) was varied by a factor of 0.1 (dash-dotted line). Only full plasma calculation is shown here

Figure 10 shows the concentration of the 18 most abundant negative ions resulting from the 'inversion' of the measured 'raw' electron density profiles, at the times immediately before and immediately after sunset (1430 UT, zenith angle $91.1^{\circ}$, Fig. $10 \mathrm{a}, \mathrm{b}$; and $1520 \mathrm{UT}$, zenith angle $95.1^{\circ}$ Fig. $10 \mathrm{c}$, d). Note that in this case, for $1520 \mathrm{UT}$, we have performed the calculations assuming the reduced concentration of atomic oxygen, $[\mathrm{O}] / 10$. Our results are consistent with the observational data and with current models of the negative-ion chemistry of the mesosphere (e.g. Thomas and Bowman, 1985; Chakrabarty and Ganguly, 1989).

At 1430 UT the most abundant negative ion below $70 \mathrm{~km}$ is $\mathrm{NO}_{3}^{-}$followed closely by $\mathrm{CO}_{3}^{-}$. There are large concentrations of $\mathrm{Cl}^{-}, \mathrm{CO}_{3}^{-}\left(\mathrm{H}_{2} \mathrm{O}\right)$, and $\mathrm{NO}_{3}^{-}\left(\mathrm{H}_{2} \mathrm{O}\right)$, and then much smaller concentrations of $\mathrm{O}_{2}^{-}, \mathrm{Cl}^{-}\left(\mathrm{H}_{2} \mathrm{O}\right)$, $\mathrm{NO}_{2}, \mathrm{HCO}_{3}^{-}, \mathrm{O}_{3}^{-}\left(\mathrm{H}_{2} \mathrm{O}\right)$ and $\mathrm{CO}_{4}^{-}$. Above $70 \mathrm{~km},\left[\mathrm{O}_{2}\right]$ is clearly dominant, followed by smaller amounts of $\mathrm{CO}_{3}^{-}$, and then still smaller quantities of $\mathrm{NO}_{2}^{-}, \mathrm{NO}_{3}^{-}$, and then 

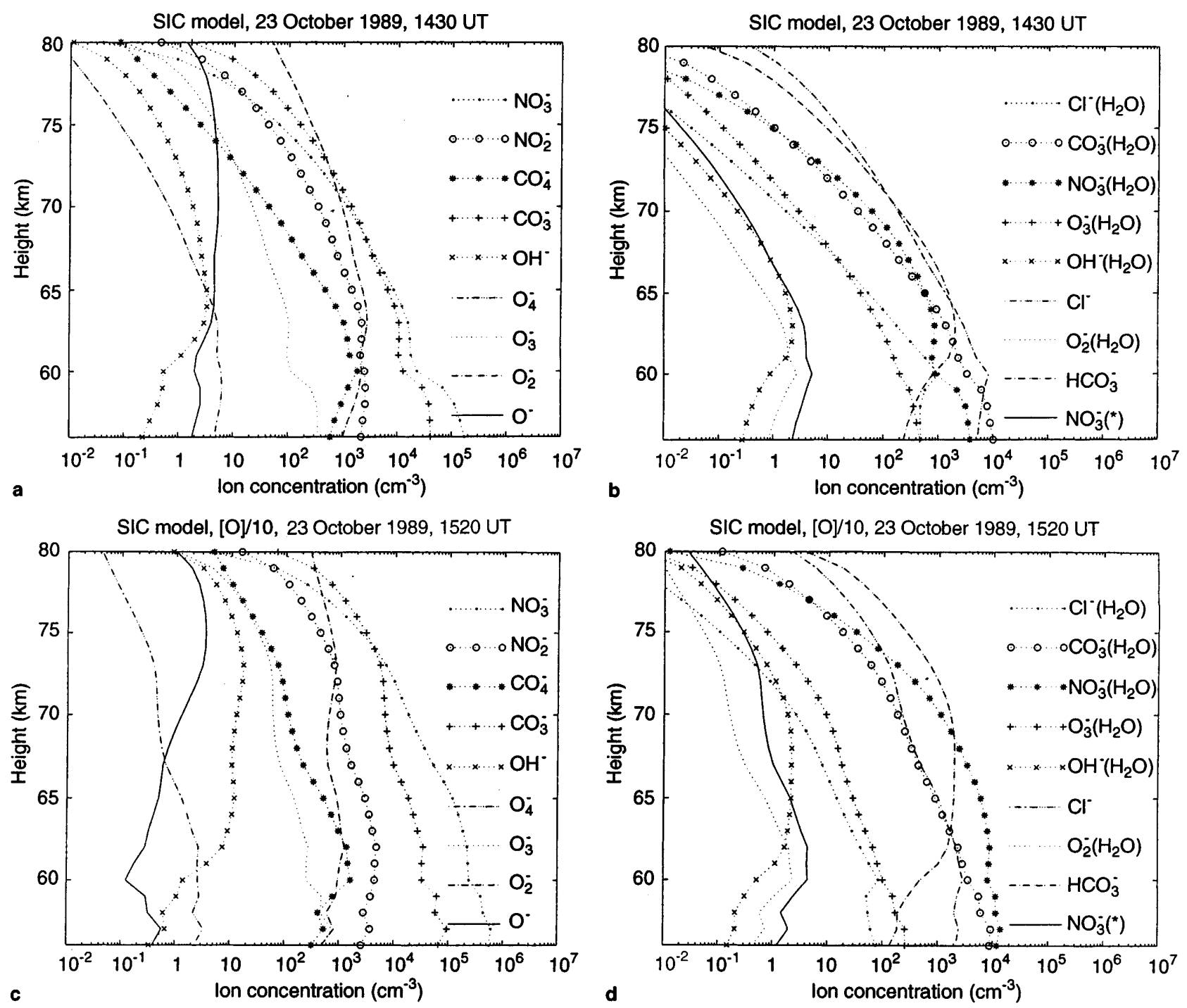

Fig. 10a-d. Concentration of the 18 most abundant negative ions at $1430 \mathrm{UT}$ (zenith angle $91.1^{\circ}$, a and b), and at 1520 UT (zenith angle $95.1^{\circ}$ c and d). AT 1520 UT the concentration of atomic oxygen was reduced by a factor of 10 from its daytime value

$\mathrm{Cl}^{-}$and $\mathrm{HCO}_{3}^{-}$. However, at these altitudes, the total concentration of negative ions is not significant as compared to the electron density.

At 1520 UT, on the other hand, we see a large increase in the concentration of most negative ions and a substantial reduction in electron concentration, when compared to the pre-sunset conditions (at $1430 \mathrm{UT}$ ). After sunset, $\mathrm{NO}_{3}^{-}$and $\mathrm{CO}_{3}^{-}$are still the most abundant ions, and $\left[\mathrm{NO}_{3}^{-}\right]$increases by almost an order of magnitude as compared to $\left[\mathrm{CO}_{3}^{-}\right]$. The concentration of the hydrated ions $\mathrm{NO}_{3}^{-}\left(\mathrm{H}_{2} \mathrm{O}\right)$ and $\mathrm{CO}_{3}^{-}\left(\mathrm{H}_{2} \mathrm{O}\right)$ also shows a large increase above $60 \mathrm{~km}$, with $\left[\mathrm{NO}_{3}^{-}\left(\mathrm{H}_{2} \mathrm{O}\right)\right] \gg\left[\mathrm{CO}_{3}^{-}\left(\mathrm{H}_{2} \mathrm{O}\right)\right]$ in the $60-72 \mathrm{~km}$ altitude range. In the 60-75 km range, moreover, $\left[\mathrm{Cl}^{-}\right] \sim$ $\left[\mathrm{CO}_{3}^{-}\left(\mathrm{H}_{2} \mathrm{O}\right)\right]$, and $\left[\mathrm{Cl}^{-}\right] \gg\left[\mathrm{CO}_{3}^{-}\left(\mathrm{H}_{2} \mathrm{O}\right)\right] \sim\left[\mathrm{NO}_{3}^{-}\left(\mathrm{H}_{2} \mathrm{O}\right)\right]$, above $75 \mathrm{~km}$. Above $65 \mathrm{~km},\left[\mathrm{HCO}_{3}^{-}\right]>>\left[\mathrm{Cl}^{-}\right]$with $\left[\mathrm{O}_{2}^{-}\right] \sim\left[\mathrm{NO}_{2}^{-}\right] \sim\left[\mathrm{HCO}_{3}^{-}\right]$up to $75 \mathrm{~km}$, and then $\mathrm{O}_{2}^{-}$and $\mathrm{NO}_{2}^{-}$become dominant. As at pre-sunset, $\left[\mathrm{O}_{2}^{-}\right]$is still very important at higher altitudes but competing with the concentrations of $\mathrm{CO}_{3}^{-}, \mathrm{NO}_{3}^{-}$, and $\mathrm{NO}_{2}$.

\section{Conclusion}

The 55-ion Sodankylä model was applied in the inversion of the raw densities measured by the UHF EISCAT radar and it appears to provide some realistic estimates of the actual electron density as well as of the equilibrium ion composition with height and zenith angle. This is supported, with various degrees of success, by the comparisons between the calculated spectral widths and the radar measurements. Solar zenith angle dependence in our model does not by itself explain the changes in the observed spectral widths. It requires the consideration of sizeable changes in the concentration of some minor neutral constituents (atomic oxygen being the best candidate) during sunset, as well as some adjustments in the neutral temperature profile given by the MSIS90 model.

At sunset we found a rapid transition from the simpler daytime composition to the more complex nighttime ion chemistry. This is clearly shown by the 
changes in the total concentration of negative ions, proportional to the spectral width in Fig. 3, and then Figs. 6 to 7. Photodetachment of negative ions, and to a lesser extent the photodissociation of heavier ions into lighter ones, are responsible for the large variation in the width of the ion-line by inducing a large reduction in both the ratio of negative ions and the average ion mass. At the sunset transition, this results in the increase of the spectral width with increasing zenith angle, and the opposite during sunrise.

Variations in the measured spectral width were seen to depend most heavily on parameters such as the temperature and the concentration of the major neutral constituents, which affect the spectral width both through the ion-neutral collision frequency and the ion chemistry. In addition, large variations of the spectral width are also seen to be caused by variations of some key minor constituents: $\mathrm{O}, \mathrm{O}_{2}\left({ }^{1} \Delta \mathrm{g}\right), \mathrm{O}_{3}$ and NO. The concentrations of these neutrals will affect the ionisation balance through ion chemistry. Although the concentration of $\mathrm{NO}$ in the auroral mesosphere is heavily dependent on the competition between transport and destruction by photochemical and precipitation processes, so that very large variations in its concentration indeed occur, we should not expect significant changes at the short time scales of the sunset transition. On the other hand, the concentration of atomic oxygen is expected to undergo a rapid reduction during sunset, below $80 \mathrm{~km}$, and in fact decreasing it by a reasonable factor of ten appears to be sufficient to roughly explain the changes in the measured spectral width.

We did not try to adjust the various model inputs for an exact match between the measured and the calculated spectral widths. Instead, we show that such a match is in fact possible by some additional 'fine- tuning' in the concentrations of other minor constituents, as well as the neutral temperature. The required changes are, of course, inside the accepted limits for the variability of the various parameters. For detailed quantitative investigations there is clearly a need for complementary measurements by other instruments. For instance, knowing the actual neutral temperature profile (from LIDAR measurements) and applying the spectral width and electron density data from the radar, one could estimate, with the help of the chemical model, the changes in the concentrations of the minor constituents. Perhaps, when available, the data from the new LIMBsatellite scanning experiments could be used to better define the concentrations of some of the relevant neutral constituents, while the others could be estimated in combination with our chemical model.

Acknowledgements. We would like to thank Päiviö Pollari of the University of Oulu for his help in the processing of the GEN11 data. EISCAT is supported by the Suomen Akatemia (Finland), the Centre National de la Recherche Scientifique (France), the Max-Planck Gesellschaft (Germany), the National Institute of Polar Research (Japan), Norges Almenraitenskapelige Forksningrad (Norway), Naturretenskapliga Forskningsradet (Sweden), and the Particle Physis and Astronomy Research Council (UK). This study was partly supported by a grant from the UK Particle and Astronomy Research Council (PPARC), to the Department of Physics at the University of Wales at Aberystwyth.

Topical Editor D. Alcaydé thanks L. Thomas and E. Thrane for their help in evaluating this paper.

\section{Appendix}

After neglecting advection and diffusion terms, the continuity equation for the electron density $n(t)$ may be written as:

$\frac{\mathrm{d} n(t)}{\mathrm{d} t}=q(t)-\alpha_{\mathrm{eff}} n(t)^{2}$

The electron production $q(t)$ is equal to the ion-pair production function $Q(t)$ divided by $\left(1+\lambda_{-}\right)$. The effective recombination coefficient, $\alpha_{\text {eff }}$, is generally assumed to be time-independent and defined by the chemical equilibrium conditions reached at times greater than the recombination time $T_{R}=1 /\left(\alpha_{\mathrm{eff}} n_{\mathrm{o}}\right)$, where $n_{\mathrm{o}}$ is the equilibrium electron density. Typically, $T_{R}$ ranges between $10 \mathrm{~s}$ and less than $2 \mathrm{~min}$ at mesospheric heights. This coefficient, however, is not unique and may vary with time. Different equilibrium compositions can be attained, at different times, as a function of the hardness of the precipitation spectrum as well as from sudden changes in the solar production function. In strict sense, moreover, the recombination coefficient is also a function of the collision cross-sections, the distribution functions of the collision partners, the reduced masses and temperature, as well as of the relative concentrations of the various positive and negative ions.

If we assume that an arbitrary production rate $q(t)$ may be represented by the sum of constant steps over a number of time intervals $\Delta t_{i}\left(=t_{i}-t_{i-1}\right)$ :

$q(t)=\sum_{i} q_{i} U\left(t-t_{i}\right)$

Function $U\left(t-t_{i}\right)$ is equal to unity in the interval $t_{i-1}<t \leq t_{i}$, and zero otherwise; $q_{i}$ is the averaged production rate over interval $\Delta t_{i}$. Equation (A1) can be solved for each interval $\Delta t_{i}$ to obtain,

$n(t)=\sum_{i} n_{\mathrm{o} i} \frac{1+a \exp \left(-2 b\left(t-t_{i-1}\right)\right)}{1-a \exp \left(-2 b\left(t-t_{i-1}\right)\right)} U\left(t-t_{i}\right)$

where $a=\left(n_{i-1}-n_{\mathrm{o} i}\right) /\left(n_{i-1}+n_{\mathrm{o} i}\right)$, with $n_{i-1}=n\left(t_{i-1}\right)$, $b=\alpha_{\mathrm{eff}} n_{\mathrm{o} i} \sim 1 / T_{R}$, and $n_{\mathrm{oi}}=\left(q_{i} / \alpha_{\mathrm{eff}}\right)^{1 / 2}$. If $\Delta t_{i} \geq T_{R}$ we may have,

$n\left(t_{i}\right)=\frac{\left(n_{i-1}+\Delta n_{i-1}\right)+\left(n_{\mathrm{o} i}-\Delta n_{\mathrm{o} i}\right)}{\left(n_{i-1}-\Delta n_{i-1}\right)+\left(n_{\mathrm{o} i}+\Delta n_{\mathrm{o} i}\right)} n_{\mathrm{o} i}$

with $\Delta n_{i-1} / n_{i-1}=\Delta n_{\mathrm{o} i} / n_{\mathrm{o} i}=\exp \left(-2 \Delta t_{i} / T_{R}\right) \ll 1$. For instance, if $1.2 T_{R} \leq \Delta t_{i} \leq 1.5 T_{R}$, this 'relative error' can not be distinguished from an experimental error of the order of $5 \%$ to $10 \%$. Therefore,

$n\left(t_{i}\right) \approx n_{\mathrm{o} i}=\left(\frac{q_{i}}{\alpha_{\mathrm{eff}}}\right)^{1 / 2}$

which is the electron density as defined by the chemical equilibrium conditions. 
C. F. del Pozo et al.: Negative ions in the auroral mesosphere during a PCA event around sunset

\section{References}

Brasseur G., and S. Solomon, Aeronomy of the middle atmosphere, D. Reidel, Dordrecht, Holland, 1986.

Burns C. J., E. Turunen, H. Matveinen, H. Ranta, and J. K. Hargreaves, Chemical modelling of the quiet summer D- and Eregions using EISCAT electron density profiles J. Atmos. Terr. Phys., 53, 115, 1991.

Chakrabarty D. K., and S. Ganguly, On significant quantities of negative ions observed around the mesosphere, J. Atmos. Terr. Phys., 51, 983, 1989.

Collis P. N., and M. T. Rietyeld, Mesospheric observations with the EISCAT UHF radar during polar cap absorption events: 1 . Electron densities and negative ions, Ann. Geophysicae, 8, 809, 1990.

del Pozo C. F., and A. D. Aylward, Ion-line in the D and E regions from EISCAT observations and the Lancaster-Sodankyla model, Adv. Space Res., 6, 905, 1998.

del Pozo C. F., J. K. Hargreaves, and A. D. Aylward, Ion composition and effective ion recombination rate in the nighttime auroral lower ionosphere, J. Atmos. Solar-Terr. Phys., 59, 1919, 1997

Dougherty J. P., and D. T. Farley, A theory of incoherent scattering of radio waves by a plasma: 3 . Scattering in a partly ionized gas, J. Geophys. Res., 68, 5473, 1963.

Fukuyama K., and W. Kofman, Incoherent scattering of an electromagnetic wave in the mesosphere: theoretical consideration, J. Geomag. Geoelectr., 32, 67, 1980.

Mathews J. D., The effect of negative ions on collision-dominated Thomson scattering, J. Geophys. Res., 83, 505, 1978.

Ogawa T., and T. Shimazaki, Diurnal variations of odd nitrogen and ionic densities in the mesosphere and lower thermosphere: simultaneous solution of photochemical-diffusive equations, $J$. Geophys. Res., 28, 3945, 1975.
Pollari P., A. Huuskonen, E. Turunen, and T. Turunen, Range ambiguity effects in a phase coded D-region incoherent scatter radar experiment, J. Atmos. Terr. Phys., 51, 937, 1989.

Ranta H., A. Ranta, S. M. Yousef, J. Burns, and P. Stauning, Dregion observations of polar cap absorption events during the EISCAT operation in 1981-1989, J. Atmos Terr. Phys., 55, 751, 1993.

Rees M. H., Physics and chemistry of the upper atmosphere, University Press, Cambridge, Great Britain, 1989.

Rietveld M. T., and P. N. Collis, Mesospheric observations with the EISCAT UHF radar during polar cap absorption events: 2 . Spectral measurements, Ann. Geophysicae, 5, 797, 1993.

Shimazaki, T., Minor constituents in the middle atmosphere, TERRAPUB, Tokyo, 1985.

Thomas L., and M. R. Bowman, Model studies of the D-region negative-ion composition during day-time and night-time, $J$. Atmos. Terr. Phys., 47, 547, 1985.

Thomas L., and M. R. Bowman, A study of pre-sunrise changes in negative ions and electrons in the D-region, Ann. Geophysicae, 4, 219, 1986.

Turunen E., EISCAT incoherent scatter radar observations and model studies of day to twilight variations in the $\mathrm{D}$ region during the PCA event of August 1989, J. Atmos. Terr. Phys., 55, 767, 1993.

Turunen E., Sodankylä ion chemistry model, in Proc. of the planning meeting for joint studies with Orsted, the EISCAT radars, and other ground based instruments, The Finnish Academy of Science and Letters, Report 54, pp. 123-128, 1996.

Turunen E., H. Matveinen, and H. Ranta, Sodankylä Ion Chemistry (SIC) Model, Sodankylä Geophysical Observatory, Report 49, Finland, 1992.

Turunen T., GEN-SYSTEM - a new experimental philosophy for EISCAT radars, J. Atmos. Terr. Phys., 48, 777, 1986. 